\title{
O ПЕРСПЕКТИВАХ ИНСТИТУТА СУДЕБНОГО ПРИМИРЕНИЯ В РОССИИ
}

\section{ABOUT THE PROSPECTS OF THE INSTITUTE OF JUDICIAL RECONCILIATION IN RUSSIA}

O. Ryabova

N. Kuznetsova

T. Matveeva

N. Kuznetsova

Summary. The article is devoted to the Institute of judicial reconciliation in Russia. The paper considers the current state and prospects of implementation of the judicial reconciliation procedure. The positive role of this institution for the Russian judicial system is highlighted. The problems of legislation regulating this procedure and law enforcement practice of this process are noted, and weaknesses of legislative norms in this area are identified. The article contains elements of comparison of the judicial reconciliation procedure with similar procedure in foreign countries and the authors ' suggestions for introducing the positive experience of these countries into the system of the Russian model of conciliation procedure. The work identifies and analyzes the reasons that prevent the judicial reconciliation procedure from being effectively integrated into the Russian judicial system. The article also contains possible solutions to these problems.

Keywords: judicial reconciliation, judicial conciliator, problems, implementation of the procedure, reconciliation of the parties, dispute resolution.
$\mathbf{K}$ онституция Российской Федерации, помимо закрепления прав и свобод, определяет еще и способы их защиты. Реализация права на защиту осуществляется как с помощью правосудия, так и с использованием внесудебных способов, в том числе примирительных, закрепленных законодательством Российской Федерации.

Практическая значимость примирительных процедур велика. В настоящее время процессуальное законодательство Российской Федерации содержит целый комплекс таких процедур.
Рябова Ольга Алексеевна

Преподаватель, ФКОУ ВО «Владимирский юридический институт ФСИН России»

frau.lelya2012@yandex.ru

Кузнецова Наталья Александровна

Старший преподаватель, ФКОУВО «Владимирский юридический институт ФСИН России»

kuz1503@yandex.ru

Матвеева Тамара Павловна

Старший преподаватель, ФКОУ ВО «Владимирский юридический институт ФСИН России»

matveeva33@mail.ru

Кузнецова Наталья Владимировна

Старший преподаватель, ФКОУ ВО «Владимирский юридический институт ФСИН России»

kuznezova-1963@mail.ru

Аннотация. Статья посвящена институту судебного примирения в России. В работе рассматриваются современное состояние и перспективы реализации процедуры судебного примирения. Освещается положительная роль указанного института для судебной системы России. Отмечается проблематика законодательства, регулирующего данную процедуру и правоприменительной практики указанного процесса, выявляются слабые стороны законодательных норм в указанной области. Статья содержит элементы сравнения процедуры судебного примирения с подобной процедурой в зарубежных странах и предложения авторов по внедрению положительного опыта этих стран в систему российской модели примирительной процедуры. Работа выявляет и дает анализ причин, которые мешают процедуре судебного примирения эффективно встроится в судебную систему России. Также статья содержит возможные пути решения указанных проблем.

Ключевые слова: судебное примирение, судебный примиритель, проблемы, реализация процедуры, примирение сторон, разрешение споров.

С 25 октября 2019 года российское законодательство установило новый вид примирительных процедур. Данная новелла получила название процедуры судебного примирения. Изменения коснулись гражданского, арбитражного и административного процессов. Указанные изменения регламентированы Федеральным Законом № 197-Ф3 «О внесении изменений в отдельные законодательные акты Российской Федерации» от 26.07.2019 г. и на его основании внесены соответствующие поправки в Гражданский процессуальный кодекс РФ, Арбитражный процессуальный кодекс РФ и Кодекс административного судопроизводства РФ. Сама реализация проце- 
дуры судебного примирения закреплена в Регламенте проведения судебного примирения, утвержденного Постановлением Пленума Верховного Суда РФ от 31 октября 2019 года № 41.

Таким образом, комплекс примирительных процедур пополнился еще одним институтом.

Разработка и внедрение на законодательном уровне различного рода примирительных процедур обусловлена возрастающей нагрузкой на судебную систему и попытку справится с этой ситуацией посредством создания комплексной системы примирительных процедур. Институт судебного примирения один из элементов этой системы. При анализе Регламента проведения примирительных процедур мы среди целей и задач данной процедуры видим содействие становлению и развитию партнерских взаимоотношений, формирование обычаев и этики делового оборота.

Процедура судебного примирения, по нашему мнению, является альтернативой частным примирительным процедурам (медиации).

Мы полагаем, что концептуальная идея законодателя при создании института судебного примирения заключалась в необходимости вовлечь суд в примирительную процедуру. Это подтверждает тот факт, что в соответствии с Регламентом, судья, рассматривающий дело, имеет возможность предложить сторонам по делу воспользоваться примирительной процедурой. Более того, примирительные процедуры должны проходить в отдельном помещении в здании суда, что тоже делает суд косвенным участником данного процесса. Основанием для проведения указанной процедуры является определение суда о проведении судебного примирения. [5] Сами стороны тоже имеют право заявить ходатайство о судебном примирении. То есть момент начала процедуры прописан законодателем весьма демократично, однако начало процедуры тоже регулируется судом. Начать примирительные процедуры возможно на любой стадии процесса и что примечательно, даже на стадии исполнения судебного акта. Теперь судья может уже на стадии определения о принятии дела к производству предложить сторонам процесса воспользоваться возможностью судебного примирения. Однако здесь сразу возникает вопрос о том, кто обязан разъяснить сторонам суть процедуры. Это проблемный момент, учитывая то обстоятельство, что процессуальное законодательство, кроме Арбитражного процессуального кодекса РФ [3], не обязывает судью разъяснять сторонам особенности участия в примирительной процедуре, их права и обязанности и права и обязанности судебного примирителя до момента их согласия или несогласия с предложенной процедурой.
Сроки судебного примирения устанавливаются и продляются судом.

Организация процедуры судебного примирения складывается из подготовительных мероприятий и собственно самой процедуры. Подготовительные мероприятия заключаются в возможности судебного примирителя ознакомиться с материалами дела, но с разрешения судьи. Примиритель организовывает процесс примирения посредством назначения встреч со сторонами, предоставления ими дополнительной информации и иных важных обстоятельств, в том числе в виде документов.

Сама фаза судебного примирения делится на стадии - открытие судебного примирения; изложение обстоятельств спора; формулирование сторонами вопросов для обсуждения; индивидуальная беседа со сторонами и их представителями; выработка сторонами результатов по урегулированию спора; оформление результатов примирения; завершение судебного примирения.[5] Необходимо уточнить, что судебный примиритель не относится к участникам судебного разбирательства и, следовательно, не вправе совершать действия, влекущие за собой возникновение, изменение, либо прекращение прав и обязанностей участников процесca. $[2,3,4]$

Завершиться судебное примирение может как по достижении цели примирительной процедуры, так и в случае отсутствия положительного результата работы судебного примирителя. Регламент указывает, что примирительные процедуры могут закончиться и по инициативе судебного примирителя, если последний сочтет, что дальнейшая работа является контрпродуктивной по разным причинам. В этом случае примиритель должен подготовить отказ в письменной форме и изложить причины, по которым он отказывается проводить дальнейшую работу.

Перечень результатов процедуры судебного примирения достаточно обширный. Он предполагает, что результатом примирительных процедур могут быть даже частичные договоренности по делу, отказ полностью или от части исковых требований, признания определенных обстоятельств, отказ от подачи жалобы в вышестоящую судебную инстанцию, мировое соглашение. [2,3,4].

Процедура судебного примирения является бесплатной для сторон, участвующих в этой процедуре. Это является огромным положительным моментом в условиях большого количества участников процесса, находящихся в стесненных финансовых условиях. Работа судебного примирителя оплачивается из средств федерального бюджета. 
В соответствии с процессуальным законодательством и Регламентом проведения судебного примирения, судебным примирителем может быть только судья в отставке, причем, если процедура примирения потребуется в Верховном суде, то судебным примирителем сможет стать только судья Верховного суда или Высшего Арбитражного Суда в отставке. [5] При определении судебного примирителя наблюдается своего рода принадлежность к определенной ступени судебной системы. Сам факт того, что примирителями могут быть только судьи в отставке, вызывает недоумение большей части юридического сообщества. Понимание того, что судья является опытным специалистом, не дает оснований полагать, что его работа в роли примирителя будет проведена лучше, чем другим лицом, обладающим достаточным опытом в юридической профессии, но не относящимся к категории судей в отставке. Полагаем, что важным критерием, по которому должны выбираться судебные примирители, должна стать подготовленность лица к работе со сторонами конфликта. Необходима специальная подготовка, изучение психологических основ личности, основ конфликтологии, умении своевременно погасить конфликт между сторонами и направить спор в нужное русло, реализуя свое предназначение В этом споре как судебного примирителя. В данной ситуации не является абсолютным, что судьи в отставке обладают необходимыми познаниями в указанных сферах. Из чего можно сделать вывод, что только многолетнего судейского опыта мало для реализации полномочий судебного примирителя. Важно отметить, что судебные примирители должны не разрешить спор, а содействовать сторонам в его разрешении. Это две абсолютно разные категории. Целью судьи является необходимость разрешить спор. А для того, чтобы содействовать разрешению спора необходимо учиться. Это совсем другая плоскость применения своих знаний о праве и профессионального опыта.

Если мы обратимся к подобному опыту зарубежного права, например, в Финляндии, то увидим, что судьи, которым доверено вести примирительные процедуры проходят специальную подготовку, прежде, чем их допускают к ведению таких процедур. Также стоит, отметить, что примирителями могут быть только судьи того суда, в котором рассматривается дело.

Если обратиться к опыту Французской республики, то там судебными примирителями могут быть лица, которые имеют практический опыт и квалификацию, не менее, чем трехлетний стаж в юридической профессии. [11]

Мы не можем перенимать буквальный опыт зарубежных стран, но учитывать важные и необходимые моменты, которые возможно применить в нашей стране, законодатели обязаны. Полагаем, что судебными примирителями могут быть разные представители юридического сообщества, которые обладают юридическим образованием, необходимым опытом и стажем в юридической профессии, не исключая и судей в отставке, но помимо этого определяющим фактором, который должен быть отражен в законодательстве, должна быть специальная подготовка лиц, которые претендуют на право стать судебными примирителями. Считаем, что законодательное ограничение возможности быть судебным примирителем только бывшими судьями в отставке является ошибочным. Это одна из самых важных проблем нового института, так как от фигуры примирителя зависит успех процедуры примирения.

В отличие от процедуры медиации, в судебном примирении расширена возможность применения судебного примирения. Сюда входит и гражданский, и арбитражный, и административный процесс. [5] Это положительно влияет на возможность воспользоваться данной процедурой большего круга заинтересованных представителей гражданского оборота.

Необходимо также отметить, что проблемой является низкая информированность потенциальных потребителей данной процедуры. Процедура примирения - процесс сложный и вместе с отсутствием информированности о нем вызывает его непонимание и, как следствие, нежелание им воспользоваться. Необходимо непременно рассказывать о таких законодательных нововведениях посредством медиаресурсов, вести разъяснительную работу, чтобы было понимание сути процедуры судебного примирения.

Следует обратить внимание на то, что параллельно с созданием самой примирительной процедуры необходимо создавать соответствующую правовую базу в разных отраслях права, чтобы прослеживалась взаимосвязь правовых норм, которая способствовала бы продвижению судебного примирения. Примером может служить семейное право. Это та отрасль, которая остро нуждается в активных примирительных процедурах, когда возникают семейные конфликты и споры, которые нужно стараться решать именно путем примирения, а не волевым судебным актом.

Анализируя нормы, регулирующие судебное примирение и судебного примирителя, мы видим, что процедура судебного примирения строится на принципах, которые указаны в Регламенте проведения судебного примирения. Среди этих принципов указываются принцип беспристрастности и независимости судебного примирителя, принцип конфиденциальности. Других норм, регулирующих морально - этическую сторону работы примирителя нет. Мы полагаем, что законодательство должно было предусмотреть в отношении судебных 
примирителей правовую норму, схожую с нормой об адвокатской тайне, которая отражена в Законе об адвокатуре и адвокатской деятельности [7], или же нормы об ответственности судебного примирителя о разглашении информации, полученной в процессе процедуры судебного примирения.

Например, французское примирительное право содержит норму о том, что судебный примиритель приносит присягу перед апелляционным судом, прежде, чем приступит к своим обязанностям. [11] Закрепление подобных норм в российском законодательстве стало бы дополнительным фактором ответственности для привлекательности института судебных примирителей со стороны потенциальных участников судебных процессов и лучшего соотношения с судебной системой. Также во Французском законодательстве о судебных примирителях содержится норма, которая обязывает примирителя раз в год отчитываться о своей работе перед представителями французского правосудия и прокуратуры. [11] Полагаем, что введение подобной нормы в российское законодательство стало бы важным элементом ответственности лиц, являющихся судебными примирителями.

В соответствии с Регламентом проведения судебного примирения предполагается, что сама процедура судебного примирения и работа судебного примирителя должна основываться на ряде принципов. К ним относятся принципы добровольности, сотрудничества, равноправия, конфиденциальности, принцип независимости и беспристрастности судебного примирителя. Принцип сотрудничества, как указывает Регламент, должен быть реализован через созидательный характер переговоров, которые проходят в обстановке доверия, взаимного уважения и конструктивного сотрудничества. [5] Реализовать данный принцип в настоящее время не представляется возможным, так как, без определенных законодательных поправок к требованиям к кандидату на должность судебного примирителя и обязательного обучения, создание на переговорах обстановки доверия и конструктивного сотрудничества затруднительно в силу отсутствия специальной подготовки.

Эффективным правовым механизмом реализации судебного примирения могла бы стать обязанность судьи, закрепленная в процессуальном законодательстве, разъяснять сторонам суть и преимущества процедуры судебного примирения.

Также, учитывая специфику определенной категории споров полагаем, что можно отступить от принципа добровольности и на законодательном уровне закрепить право судьи, который ведет процесс, обязать стороны обратиться к судебному примирителю. Это не значит, что стороны обязательно должны примириться, но ис- пользовать возможность сесть за стол переговоров они могут. Это дало бы возможность сторонам хотя бы попробовать договориться. Такой подход был бы полезен при рассмотрении дел, связанных, с семейными и трудовыми спорами. Подобный опыт существует во Французской республике и судьи по определенным категориям дел обязывают стороны прибегнуть к попытке судебного примирения. $[10,11]$ Это даст шанс сторонам конфликта попытаться достичь соглашения с минимальными потерями и позволит сделать процедуру популярной среди лиц, участвующих в судебном производстве.

Пока остается резюмировать лишь то, что процедура судебного примирения, формально встроенная в судебную систему России, рискует повторить печальный, на настоящий момент, опыт института медиации.

Институт судебного примирения имеет определенную схожесть с институтом медиации. Напомним, что медиация - это тоже примирительная процедура, которая регламентируется российским процессуальным законодательством и Федеральным Законом № 193-Ф3 «Об альтернативной процедуре урегулирования споров (медиации)». Закон об альтернативной процедуре урегулирования споров был принят в 2010 году, и процедура медиации за прошедшее десятилетие так и не стала востребованной среди участников судебных процессов. Низкая эффективность медиации явилась следствием серьезных недостатков в законодательном обосновании процедуры и правоприменительной практике.

Законодатель, не сумев добиться эффективности применения процедуры медиации, обладающей серьезными недостатками, должен не допустить подобной участи для института судебного примирения.

Создание реально работающего законодательства, продуманного процесса правоприменения норм о процедуре судебного примирения стало бы переломным моментом в восприятии института судебного примирения и возможности обращения за разрешением конфликта к посредникам. Понимание сути процедуры судебного примирения, доверия к лицу, осуществляющему примирительную процедуру, положили бы начало активного развития указанного института и достижения целей, которые поставлены перед процедурой судебного примирения - достижения взаимоприемлемого результата и урегулирования конфликта с учетом интересов сторон.

Крепкий, слаженно работающий на основе грамотного законодательства механизм судебного примирения в рамках комплекса примирительных процедур, встроенных в судебную систему смог бы стать эффективным инструментом разрешения споров в России. 


\section{ЛИТЕРАТУРА}

1. Конституция Российской Федерации (принята всенародным голосованием 12 декабря 1993 года) // Российская газета. № 237 25.12.1993 г.

2. Гражданский процессуальный кодекс Российской Федерации от 14 ноября 2002 г. № 138-Ф3 // Собрание законодательства Российской Федерации от 18 ноября 2002 г. № 462, ст. 4532.

3. Арбитражный процессуальный кодекс Российской Федерации от 24 июля 2002 г. № 95-Ф3 // Собрание законодательства Российской Федерации от 29 июля 2002 г № 30, ст. 3012.

4. Кодекс административного судопроизводства Российской Федерации от 8 марта 2015 г. № 21-Ф3 // Собрание законодательства Российской Федерации от 9 марта 2015 г. № 10, ст. 1391.

5. Федеральный Закон от 27.07.2010 № 193-Ф3 «06 альтернативной процедуре урегулирования споров с участием посредника (процедуре медиации)» // Российская газета. № 16830.07 .2010

6. Федеральный Закон от 31.05.2002 № 63 - Ф3 «0б адвокатской деятельности и адвокатуре в Российской Федерации (в ред. от 29.07.2017) // Российская газета. № 100 05.06.2002.

7. Постановление Пленума ВС РФ от 31 октября 2019 г. № 41 «0б утверждении регламента проведения судебного примирения» // Российская газета. № 254 12.11.2019

8. Беспалов, Ю. Ф. Комментарий к ГПК РФ (постатейный, 3 - изд., перераб. и доп.), — «Проспект», 2020 г.

9. Лескина, Э.И. Перспективы и проблемы деятельности судебных примирителей и медиаторов при урегулировании трудовых споров // Арбитражный и гражданский процесс. - 2019.— № 4.—C. 49-53

10. Соловьев, А. А. Процедуры судебного примирения в Гражданском процессуальном кодексе Французской республики // Закон.—2015 № 3 - Ст. $150-164$

11. Соловьев, А. А. 06 институте судебного примирителя во французском гражданском процессе // Вестник Университета имени 0 . Е. Кутафина. - $2017-$ № $3-$ Ст. 107-113

\footnotetext{
( Р Рябова Ольга Алексеевна ( frau.lelya2012@уandex.ru ), Кузнецова Наталья Александровна ( kuz1503@yandex.ru ),

Матвеева Тамара Павловна ( matveeva33@mail.ru ), Кузнецова Наталья Владимировна ( kuznezova-1963@mail.ru ).
}

Журнал «Современная наука: актуальные проблемы теории и практики»

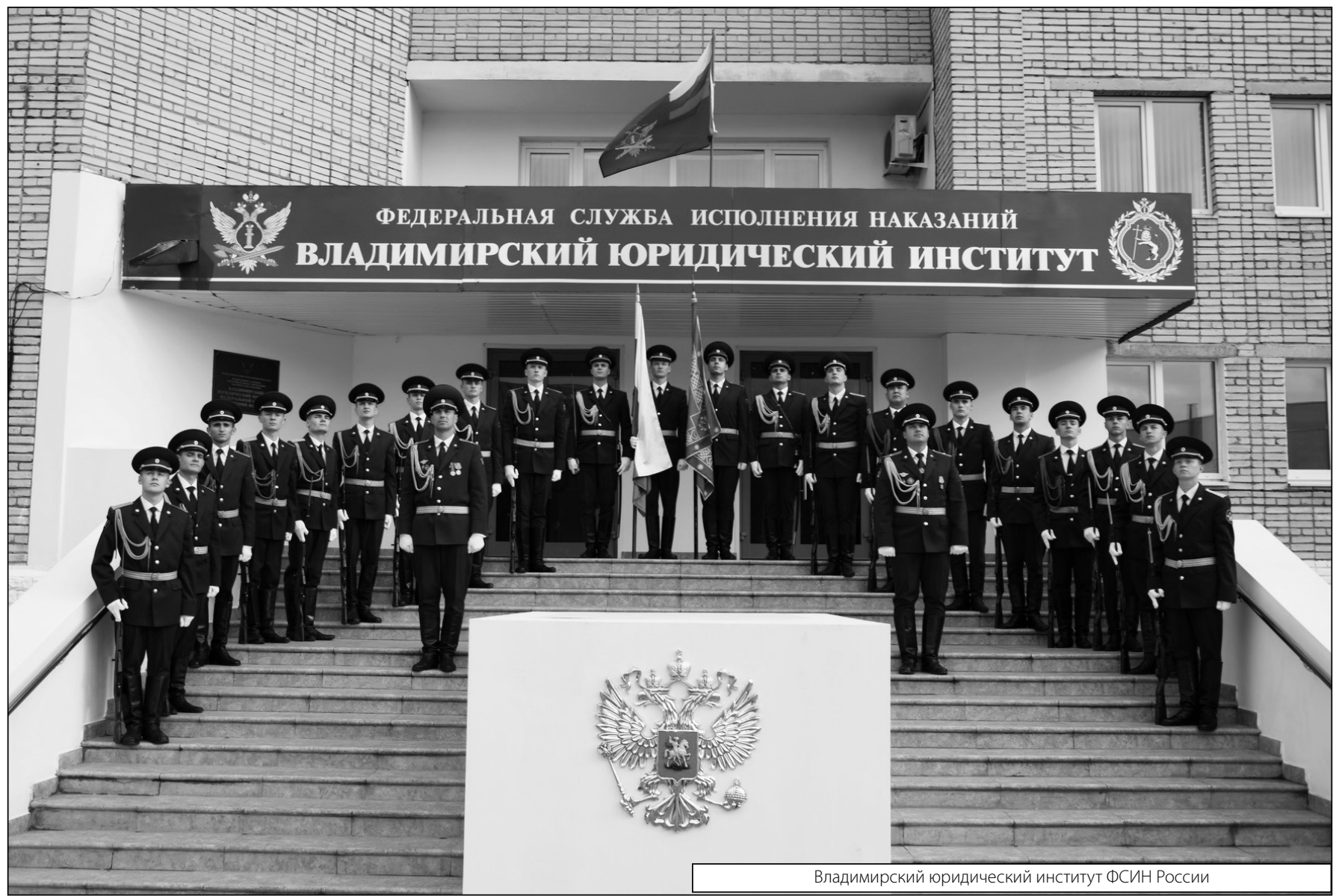

